\title{
0 design, a arte e 0 artesanato deslocando o centro
}

\section{Design, art and craftwork moving the center}

\author{
Adriana Carla Avelino Mazza \\ Ana Silvia Rocha Ipiranga ${ }^{2}$ \\ Ana Augusta Ferreira de Freitas ${ }^{3}$
}

\section{Resumo}

Partindo da idéia de que os objetos do cotidiano comunicam algo sobre elementos da cultura, dos benefícios, da funcionalidade e do valor do produto, sendo o design uma forma expressiva assimilável à arte, este trabalho tem por objetivo apresentar exemplos de aplicação do repertório semântico do artesanato folclórico brasileiro enquanto forma de construção de identidades para os produtos nacionais. Para tanto foi utilizado como enfoque metodológico a abordagem visual, através da observação e leitura de imagens fotográficas. Observou-se que no desenvolvimento dos produtos há uma preocupação em manter características originais do produto artesanal, como materiais, processo de fabricação manual e técnica. Desta forma, grande parte do design e produtos analisados não visa à comercialização em larga escala, gerando, contudo, significados e propondo inovações. Estas leituras do produto artesanal foram mescladas a uma nova releitura da forma ou do uso onde foram reforçados os aspectos estético, simbólico e artístico ao interpretar e veicular o repertório semântico do artesanato folclórico brasileiro, enquanto construção de identidade, estilo de vida, expressão de valores e cultura.

Palavras-chave: Design, Artesanato, Abordagem Visual

\begin{abstract}
This work aims at producing examples of handcraft semantic repertoire in connection to indigenous folklore manufactured products. Research results might be useful for the design of regional folklore based products, giving them a better identity. A methodology based on a visual approach is used to observe and categorize evidences from a set of photographic images. It was found that manufactured product design reinforces meanings related to the original craftwork like their rough materials, manual production process and techniques. Little care is taken of innovative design induced procedures to allow large scale production. Given that, this paper explores in greater depth aspects related to functional and geometric characteristics of manufacture craftwork like products, stressing its esthetics, symbolic and artistic values imbedded in their Brazilian regional folklore semantic repertoire. A greater emphasis on the use of those design resources is suggested as a route for identity construction, lifestyle reinforcement, values expression and cultural dissemination by both producers and clients.
\end{abstract}

Keywords: design, craftwork, visual approach

\footnotetext{
1 Mestre em Administração - UECE; Vínculo: Universidade Estadual do Ceará - UECE / Faculdade Integrada do Ceará - FIC. Endereço: Rua Mário de Alencar Araripe, 1750, casa 800 - Seis Bocas - Fortaleza/CE. CEP. 60833-500. E-mail: adriana.a.mazza@gmail.com

2 Mestrado Acadêmico em Administração. Coordenadora do Laboratório Tecnologias Digitais e Pesquisa Qualitativa Universidade Estadual do Ceará - Endereço: Av. Paranjana, 1700, Campus do Itaperi - Fortaleza-CE - Brasil. CEP.: 60740-000. E-mail: anasilviaipi@uol.com.br.

3 Doutora em Engenharia de Produção (UFSC). Professora Titular, Universidade Estadual do Ceará. Endereço: Av. Paranjana, 1700, Campus do Itaperi, Centro de Estudos Sociais Aplicados. CMAAd, Fortaleza-CE, Brasil. CEP: 60740-000. Email: freitas8@terra.com.br

Artigo recebido em novembro de 2006 e aceito para publicação em janeiro de 2007
} 


\section{Introdução}

Produtos artesanais têm sido buscados por antropólogos sociais, à medida que podem ser associados à própria cultura da humanidade desde os tempos mais remotos. É possível, inclusive, afirmar que a maioria dos objetos contemporâneos são versões transformadas de objetos históricos antigos. No entanto, os produtos estão continuamente sofrendo transformação, fruto do efeito da combinação de diferentes fatores. O artesanato, por exemplo, tem sido afetado e modificado pelos efeitos tecnológicos, pelas mudanças nas condições sociais, pelos conceitos de marketing e pelas iniciativas de designers.

O estudo da cultura de bens materiais encontra força no fato de que os objetos refletem as características de uma determinada era. Eles podem reproduzir os padrões estéticos, as implicações tecnológicas e a estrutura cultural das sociedades. Isso significa que o que é transferido e veiculado pelos objetos constitui uma parte da própria herança social. Nesse sentido, a importância e a responsabilidade do designer no desenvolvimento de produtos são destacadas à medida que a sua performance é crucial à interpretação dos requerimentos simbólicos, práticos e técnicos que permeiam a vida em um determinado tempo e espaço social.

Paralelo a essa discussão está a bem promovida e aceita opinião de que uma quantidade significativa de informação cultural pode ser encontrada em objetos artesanais. Profissionais de design cuja função seja interferir no processo de desenho e desenvolvimento de produtos industriais têm também a responsabilidade de reutilização dessa informação cultural do artesanato a fim de enfatizar a sua importância e valor.

Nesse sentido, este artigo tem como objetivo apresentar, através da observação e leitura de imagens fotográficas, o repertório semântico do artesanato folclórico brasileiro, interpretado, modificado e veiculado como construção de identidade, estilo de vida e expressão de valores e cultura. Como questão de pesquisa, coloca-se: como o design pode utilizar o repertório semântico do artesanato folclórico brasileiro na configuração de produtos com uma nova linguagem, que será decodificada pelos consumidores como uma identificação do produto nacional, localizando o Brasil como o centro em torno do qual nos organizamos e produzimos? O artigo está estruturado nas seguintes seções: revisão da literatura de suporte à investigação, descrição do processo metodológico segundo a abordagem visual, apresentação da observação e leitura das imagens fotográficas e, por fim, as considerações finais do artigo.

\section{Da arte e do artesanato ao desenho industrial}

A obra de arte deita raízes profundas na realidade - natural, psíquica e histórica. Sabe-se que na gênese de uma obra de arte se dá um ato de percepção ou de memória de um momento vital para a consciência de um artista. Para a formalização verbal ou gráfica desse ato concorrem sensações e imagens, afetos e idéias, movimentos internos que se formam em correlação estreita com o mundo sentido, figurado e pensado. A arte está para o real assim como o real está para a idéia. O conceito de mimese abre caminho para a idéia de arte como percepção análoga a certos perfis da experiência (BOSI, 1999). Conhecer quem mimetiza, como, onde e quando é inerente ao discurso sobre o realismo na arte. Até o século XVII, a estética discutia o belo como perfeição, o objeto artístico era contemplado como ocorrência única no sentido de uma imitação perfeita.

Ao artesão, assim como ao artista, também cabia a função da concepção e execução de objetos únicos (CARDOSO, 2004), com suas mãos hábeis imprimia seu estilo próprio na confecção de peças exclusivas. A partir do século XVIII, o modo de proceder industrial, pelo qual a lógica de acumulação de capital passa a ser exercida pela produção industrial, tornou anacrônicos os conceitos de arte vigentes, já que não se pressupunha o uso da máquina na composição artística. $\mathrm{O}$ novo modo de organizar a relação produção/consumo alterou conceitos, valores e comportamentos tradicionais, estabelecendo polêmicas (BIGAL, 2001). As transformações ocorridas também transformaram o objeto, pela implicação de novas relações entre a finalidade conceitual e os processos de realização prática.

Com a Revolução Industrial, surgiram muitas novas indústrias que aplicavam processos mecanizados à produção. Os objetos passaram a ser produzidos em larga escala, com novos materiais, utilizando novas 
técnicas, e a decoração e ornamentação dos objetos, que até então eram vistos como sinal de perícia e virtuosismo dos artesãos, passaram a ser produzidos em série. $\mathrm{O}$ uso indiscriminado de ornamentos, numa tentativa de acrescentar valor a produtos simples, acaba por criar um abismo entre estilo e função (HESKETT, 1998), bem como, a facilidade de reprodução mecânica passa a possibilitar a produção de imitações perfeitas, pela falta de intervenção do elemento artesanal, gerando problemas para a indústria (CARDOSO, 2004).

Assim, em virtude de sua origem e função, o desenho de produtos industriais surge sob a ocorrência de muitas polêmicas em que estiveram envolvidas as noções de arte e técnica. Essas polêmicas atravessam o período contemporâneo, e do elenco de proposições mais recentes, destacam-se duas em especial: o caráter utilitário da técnica e o caráter não utilitário da arte (BIGAL, 2001). Historicamente, porém, a passagem de um tipo de fabricação, em que o mesmo indivíduo concebe e executa o artefato, para outro, em que existe uma separação nítida entre projetar e fabricar constitui um dos marcos fundamentais para a caracterização do design (CARDOSO, 2004).

No Congresso realizado pelo International Council of Societies of Industrial Design (ICSID), em 1973, o design foi definido como uma atividade no extenso campo da inovação tecnológica. Uma disciplina envolvida nos processos de desenvolvimento de produtos, ligada às questões de uso, função, produção, mercado, utilidade e qualidade formal ou estética de produtos industriais, com a ressalva de que a definição de design se daria de acordo com o contexto específico de cada nação (BRASIL, 1997).

No Brasil, no Projeto de Lei n⿳⺈ 3.515, de 1989, apresentado pelo deputado Maurílio Ferreira Lima, constava que a profissão de designer é caracterizada pelo desempenho de atividades especializadas de caráter técnicocientífico, criativo e artístico, visando à concepção e ao desenvolvimento de projetos e mensagens visuais. Em design, projeto é o meio em que o profissional, equacionando de forma sistêmica, dados de natureza ergonômica, tecnológica, econômica, social, cultural e estética, responde concreta e racionalmente às atividades humanas. Os projetos elaborados por designers são aptos à seriação ou industrialização e estabelecem relação com o ser humano, no aspecto de uso ou de percepção, de modo que atendam a necessidades materiais e de informação visual.

\section{Do desenho industrial ao "design-arte"}

A partir da Segunda Guerra Mundial, a produção em grande escala de bens materiais, deu lugar à produção de bens imateriais (serviços, informações, símbolos, estética e valores) que caracterizam a dita sociedade pósindustrial. Segundo Heskett (1998), nosso ambiente visual imediato é dominado pelos produtos de métodos industriais de fabricação. Eles constituem a paisagem da vida cotidiana, compreendendo em sua totalidade uma complexa trama de funções e significados, na qual nossas percepções do mundo, nossas atitudes e senso de relacionamento com ele estão intimamente entrelaçados. A cultura e os valores emergentes nesta atual sociedade são diferentes dos valores que foram cultivados na sociedade industrial. As formas, as cores e os sons são tão indispensáveis ao homem pós-moderno quanto a substância e a funcionalidade.

Nesse contexto, os objetos tornaram-se um importante canal de comunicação, através dos quais os indivíduos expressam valores, status e personalidade. O caráter distintivo é dado pelo produto seriado e não mais só pela peça única. À medida que um objeto se aperfeiçoa e exaure a sua aplicação prática, acentua-se a exigência de que seja mais refinado, original, primoroso e agradável aos sentidos. Por exemplo, até algumas décadas atrás, os relógios se distinguiam principalmente pelo grau de precisão. Hoje, com a máxima precisão do relógio quartzo cresce a exigência de que ele se distinga no design. O prazer estético resultante, a ostentação da beleza e o valor para coleção se juntam à tradicional função técnica do relógio, que consistia em dar a hora certa. Considerações análogas valem para o automóvel, para o mobiliário, a decoração, utensílios, vestuário etc.

A linguagem visual adotada no projeto de um produto reflete um universo semântico e simbólico que o "designer-artista" decidiu comunicar através deste produto. Os objetos comunicam algo ao expressar um repertório semântico sobre elementos da cultura, da funcionalidade, dos benefícios e do valor do produto, sejam estes oferecidos por funções práticas, estéticas ou por funções simbólicas (MAGALHÃES, 1997). O projeto de 
produtos industriais hoje deve ser necessariamente contextualizado, atendendo às características econômicas, sociais e culturais dos consumidores. Nesse sentido, já não se faz referência a desenho de produto, mas a desenho ambiental, no qual o produto e suas qualidades contracenam com o consumidor e sua capacidade de processar informação (FERRARA, 1999).

O interpretativismo, com o designer posicionando-se no baricentro desse processo criativo, passa a ser caracterizado como um dos eventos mais importantes nas sociedades pós-industriais. O objeto não é mais o referente, é a mensagem. O design torna-se então uma forma expressiva assimilável à arte, quando esta é encarada como uma transformação, uma mudança de forma, da forma como se apresenta na natureza para a forma da linguagem (BIGAL, 2001). Hoje, torna-se necessário, ao mesmo tempo, manufaturar o produto e a cultura, além do significado atribuído ao produto, já que este reflete um universo semântico e simbólico que o "designer-artista" comunica através da concepção do projeto. Nesse contexto, Paz (1996) alerta para a uniformização da técnica, pois com a disseminação da informação de maneira global, as influências acabam por serem as mesmas em todo lugar, aplanando as diferenças entre as diversas culturas e estilos nacionais.

\section{0 "design-arte" deslocando o centro através do artesanato}

O produto industrial traz em seu bojo a própria destruição, com a obsolescência planejada, manipulando o consumo, de modo que garanta o escoamento do resultado de uma sempre crescente produtividade industrial, gerando a obsolescência de desejabilidade (NIEMEYER, 2000). Por outro lado, a globalização pressupõe o interesse das empresas em padronizar os desejos de consumidores nos mais diversos países ou regiões e em expandir o chamado mercado global. Dessa forma, uma fonte de vantagem competitiva passou a ser a capacidade de produzir produtos de alta qualidade a custos baixos, visto que consumidores globais sacrificariam suas preferências por esse tipo de produto (FARIA; GUEDES, 2004).

A evolução das instâncias democráticas e os interesses de elevação dos padrões de competitividade ensejam o surgimento de códigos de defesa do consumidor, que fazem com que grandes empresas revejam suas relações com o mercado. Com isso, são criados "serviços de atendimento ao consumidor" para haver a interlocução direta produtor/consumidor, na tentativa de evitar conflito e sanar reclamações (NIEMEYER, 2000). Para Faria e Guedes (2004), alguns grupos são tratados pelas disciplinas de marketing como "mercados" ou "segmentos de mercado" que devem ser conquistados. Esses autores propõem tratar grupos no "mercado", ou em certos domínios do "ambiente externo", como organizações que resistem estrategicamente ao crescente poder e aos abusos das grandes corporações no contexto da globalização.

Inserido nessa realidade está o mercado brasileiro, num processo de integração com os mercados internacionais, o que ressalta a importância de se desenvolver produtos com uma linguagem própria, oriunda da cultura, com signos próprios, mas de leitura universal, sintetizando a diversidade, acentuando a identidade nacional (NIEMEYER, 2000). Nesse enfoque, o design assume um papel integrador entre definição de identidade e comunicação de valor. Vinculado ao sistema industrial de produção em massa, o design não se restringe ao plano de ferramenta tecnológica que ajuda a indústria a produzir mais ou ao plano do marketing que ajuda a indústria a vender mais, mas liga-se ao mercado-organização, fortalecendo a cultura local através da valorização de seus signos e significados.

Considerando que todas as culturas produzem objetos, e que segundo Ribeiro (1989) esta produção é resultado de quatro etapas: 1) a sua concepção na mente do indivíduo; 2) o comportamento tendente à sua realização; 3) o produto resultante, que, por sua vez, 4) invoca a concepção original, cabe estudar o artesanato como elemento da cultura, cujo procedimento e iconicidade identificam essa dita cultura não apenas por sua concepção formal, mas também pelo código de seus significados simbólicos. Desta maneira, ainda por uma ótica de internacionalização, a tradição do artesanato surge como forte referência e arma competitiva (Cf. VOGT, 2002), que através de suas formas reproduz a história de vida do povo, construindo uma memória forte e material. O artesão é então tido como capaz de interpretar os desejos e necessidades do momento cultural da sua comunidade e o artesanato como algo dinâmico, sujeito às mudanças de acordo com as novas necessidades de uso (BOLOGNINI, 1998). 
O processo artesanal está ligado à produção manual de peças únicas ou, pelo menos, de peças que fazem parte de uma pequena série, que fogem da padronização pela interferência de fatores imprevisíveis, como o estilo individual de cada artesão ou mesmo pelo uso dos materiais, que podem apresentar variações. $\mathrm{O}$ artesanato apresenta uma característica de produto utilitário, relacionada com a sua própria origem e que determina o sentido de sua existência. Bolognini (1988) classifica o artesanato em "erudito", que ocorre quando se tem o artesanato dirigido e ensinado, e o "folclórico", quando a atividade é exercida de forma espontânea, o conhecimento de materiais e técnicas é transmitido pela herança e pela história oral, sendo esse último o que considera as particularidades constitutivas da formação social de uma comunidade, de seu tempo e espaço.

Considerando esse contexto, coloca-se a questão: como o design utiliza o repertório semântico do artesanato folclórico brasileiro na configuração de produtos com nova linguagem, que será decodificada pelos consumidores como identificação do produto nacional, localizando o Brasil como o centro em torno do qual nos organizamos e produzimos?

O termo centro implica a existência de uma periferia. A utilização desses conceitos nos permite pensar em um modelo em três dimensões em que diferentes núcleos agregam, cada um, os seus satélites e giram, por sua vez, em torno de núcleos mais poderosos, ocupando ao mesmo tempo a posição de centro do seu pequeno sistema e periferia do sistema maior (CARDOSO, 2004). O Brasil pode ser considerado periférico em relação a alguns países e central em relação a outros, e mesmo dentro do país existem regiões centrais e periféricas. Para o designer brasileiro, essa constatação revela a dificuldade que se enfrenta quando se busca uma referência para a criação de uma linguagem visual que gere identidade aos produtos nacionais, os quais ainda assim estejam adequados a padrões tecnológicos internacionais e inseridos em tendências globais.

Niemeyer (2000, p.63) historia que "Nos anos 50, os industriais brasileiros sequer sabiam direito o que era design". Com o crescimento da atividade econômica e industrial brasileira, nessa época, surge a necessidade de formar profissionais com a qualificação adequada para suprir a demanda por projetos de produtos e de comunicação visual. Surgia também a concepção da importância de criar uma linguagem original, com elementos visuais próprios, oriundos da nossa cultura, com signos próprios, mas de leitura universal. Uma das soluções mais interessantes da inserção do design no Brasil surgiu na área do mobiliário, na seqüência de propostas nacionalistas de Joaquim Tenreiro e Sérgio Rodrigues, na segunda metade do século XX.

Tenreiro defendia uma produção ao mesmo tempo artesanal e modernista, de nível internacional, mas de fortes características nacionalistas (FIG. 1). Os móveis criados por Tenreiro nessa época trazem o uso característico de madeiras de lei, como jacarandá, e de palhinha, materiais que remetem a mais antiga tradição moveleira brasileira, datada da época colonial. Dentro dessa concepção, Sérgio Rodrigues projetou a poltrona mole (FIG. 2) fabricada em jacarandá maciço e couro. Essa poltrona remete a certa brasilidade não somente nos materiais e na alusão formal à rede de dormir, mas através de todo um discurso semântico e gestual sobre o jeito despojado, informal e bonachão de se sentar e de se comportar, que se tornou um dos valores mais fortes da cultura brasileira no pós-guerra (CARDOSO, 2004). 


\section{FIGURA 1 - Cadeira recurva de espaldar alto Design de Joaquim Tenreiro, 1949. \\ Coleção Jones Bergamin (RJ).}

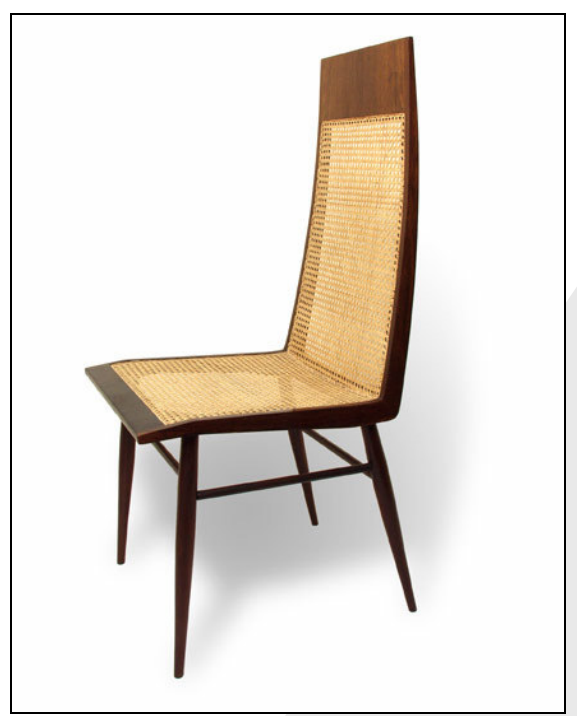

Fonte: <www.bndes.gov.br>.

FIGURA 2 - Poltrona mole

Design de Sérgio Rodrigues, 1963.

Coleção Sérgio Rodrigues (RJ).

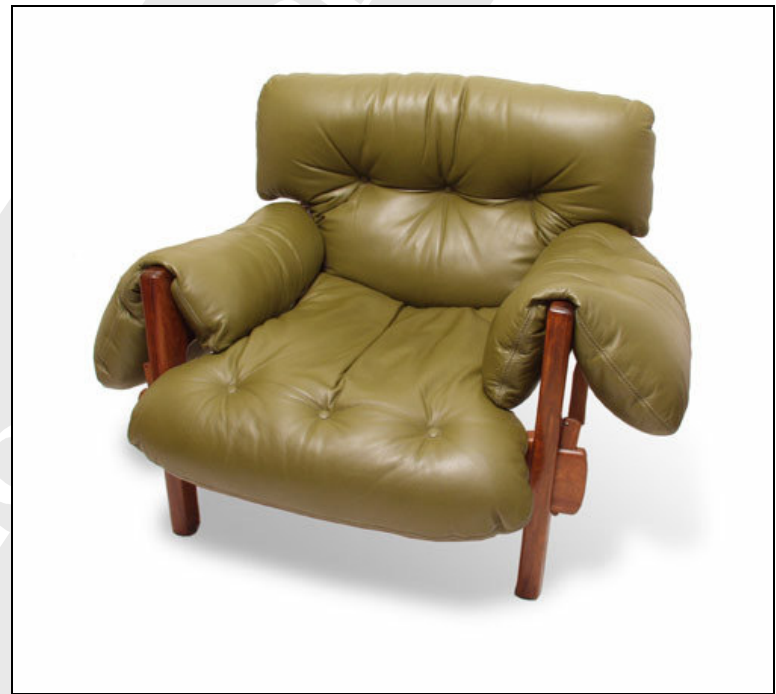

Fonte: <www.bndes.gov.br $>$.

\section{Abordagem metodológica}

Este artigo tem como objetivo apresentar, através do uso de imagens fotográficas, o repertório semântico do artesanato folclórico brasileiro, interpretado e veiculado como construção de identidade, estilo de vida e 
expressão de valores e cultura. Para tanto, foi utilizada a abordagem visual como enfoque metodológico, na qual o pesquisador, ao estudar um fenômeno social, utiliza imagens fotográficas como fonte de coleta e análise de dados (MENDONÇA; BARBOSA; DURÃO, 2004). A utilização de fotografias na pesquisa qualitativa se dá tanto no âmbito do trabalho de campo quanto na pesquisa documental (VERGARA, 2004) sendo a fotografia um documento com capacidade de conter informação de uma maneira econômica e confiável, tornando possível uma catalogação mais eficiente de informações.

As fotografias, como elementos formativos da vida social (CAUFIELD, 1996) assumem um papel similar às narrativas etnográficas, possibilitando ilustrar como a adoção do repertório semântico e simbólico do artesanato folclórico brasileiro constrói e veicula a identidade brasileira para os produtos nacionais. Através do método visual, realiza-se uma ilustração de como se pode adotar o repertório semântico dos produtos do artesanato folclórico brasileiro como forma de construir uma identidade para os produtos nacionais. Para tanto, são utilizadas fotografias de produtos desenvolvidos segundo essa proposta, as quais foram obtidas na Internet no site $A$ Casa, especializado na área de design.

O projeto de design de grande parte dos produtos selecionados para este artigo não tinha como finalidade a comercialização em larga escala, reforçando o aspecto estético, simbólico e artístico do produto ao elaborar significados originais. Foram considerados para a análise, por meio da observação e leitura dos dados visuais (fotografias) selecionados, elementos que pudessem comunicar a identidade do produto, como por exemplo, a aplicação de materiais, forma, iconografia e técnica de produção.

\section{A observação e leitura das imagens fotográficas}

Foi possível observar que no desenvolvimento dos produtos há preocupação em manter características originais do produto artesanal, como materiais, processo de fabricação manual e técnica, mesclando-os a uma nova leitura da forma ou do uso. São exemplos: a) o colete criado a partir do desenho de selas de cavalo (FIG. 3), que manteve o couro como material e a técnica de fabricação utilizando a costura com tiras finas de couro; b) o sousplat em capim dourado (FIG. 4), que possui a forma similar aos cestos até então manufaturados pelos artesãos, mas que com uma nova leitura da forma permitiu um novo uso; c) o vestido com a renda de bilro confeccionada manualmente com linha de algodão (FIG. 5), como as rendas das toalhas de mesa, mas na cor preta e aplicada em peças sofisticadas do vestuário feminino.

Observam-se também casos onde, além de novas formas e usos, os produtos desenvolvidos foram confeccionados com novos meios de produção e materiais, mas foram mantidos aspectos do repertório semântico dos produtos artesanais. É o que se pode observar nos itens de papelaria (FIG. 6) desenvolvidos pela designer Heloísa Crocco, onde foram repassados detalhes do grafismo de cerâmicas dos índios guaranis, gerando significados e propondo inovação tanto do ponto de vista estético quanto técnico. 
FIGURA 3 - Colete de couro caprino

Colete criado pela designer Lia Mônica Rossi, a partir do desenho de selas de cavalo. Confeccionado por artesão anônimo de Ribeira das Cabaceiras, Paraíba, 1998.

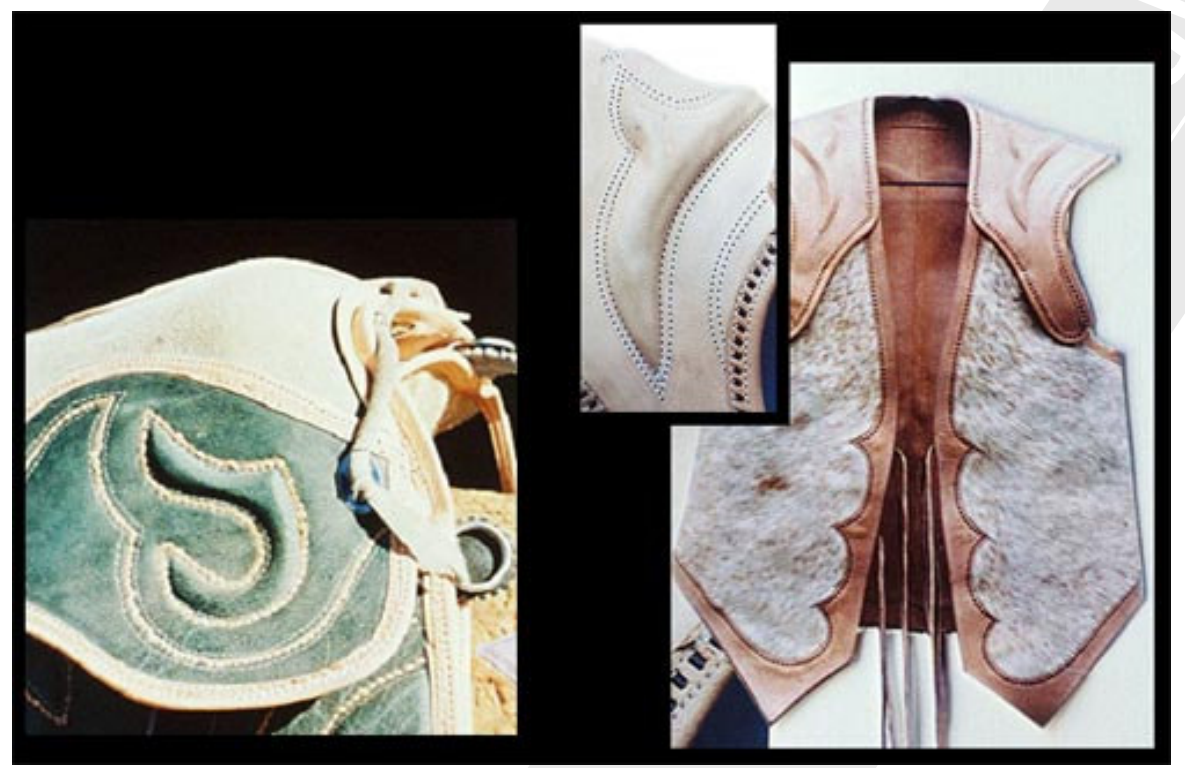

Fonte: <www.acasa.org.br>.

FIGURA 4 - Sosplat em capim dourado

Sousplat em capim dourado, costurado com fibra de buriti. Trabalho orientado pelo designer Renato Imbroisi e confeccionado por artesãos de Jalapão, Tocantins, 1999.

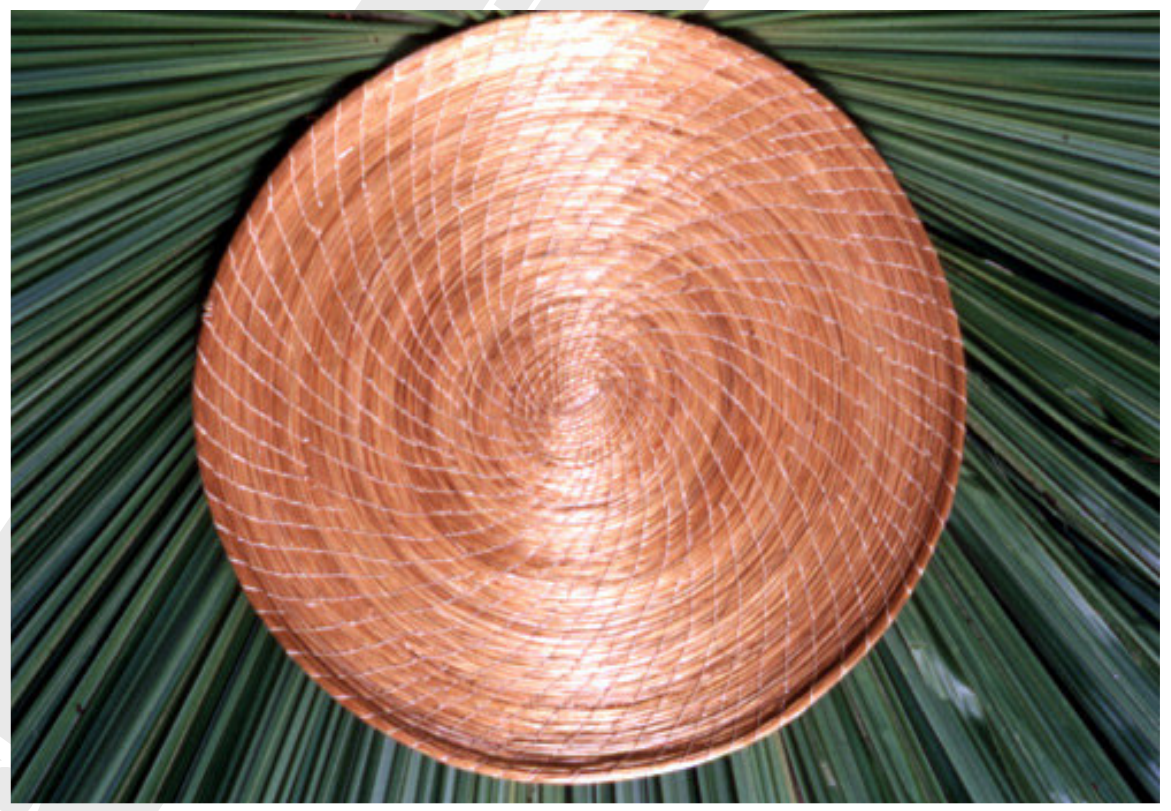

Fonte: <www.acasa.org.br>. 


\section{FIGURA 5 - Vestido com renda de bilro}

Peça criada por Walter Rodrigues, com aplicações de renda de bilro confeccionadas pelas artesãs da Associação das Rendeiras de Morros da Mariana, Piauí, 2001.

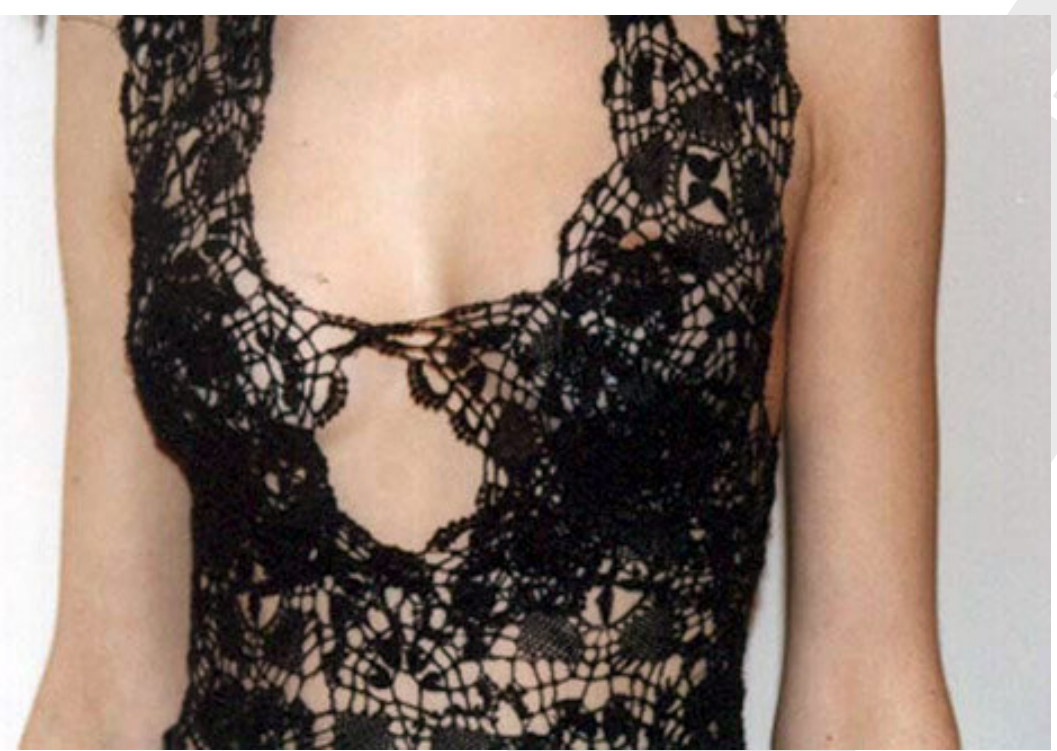

Fonte: <www.acasa.org.br>.

FIGURA 6 - Produtos com grafismo dos índios guaranis

Objetos desenvolvidos sob a coordenação da designer Heloísa Crocco, onde detalhes do grafismo dos índios guaranis foram transpostos de cacos de cerâmicas e repassados para itens de papelaria. Projeto Mão Gaúcha.

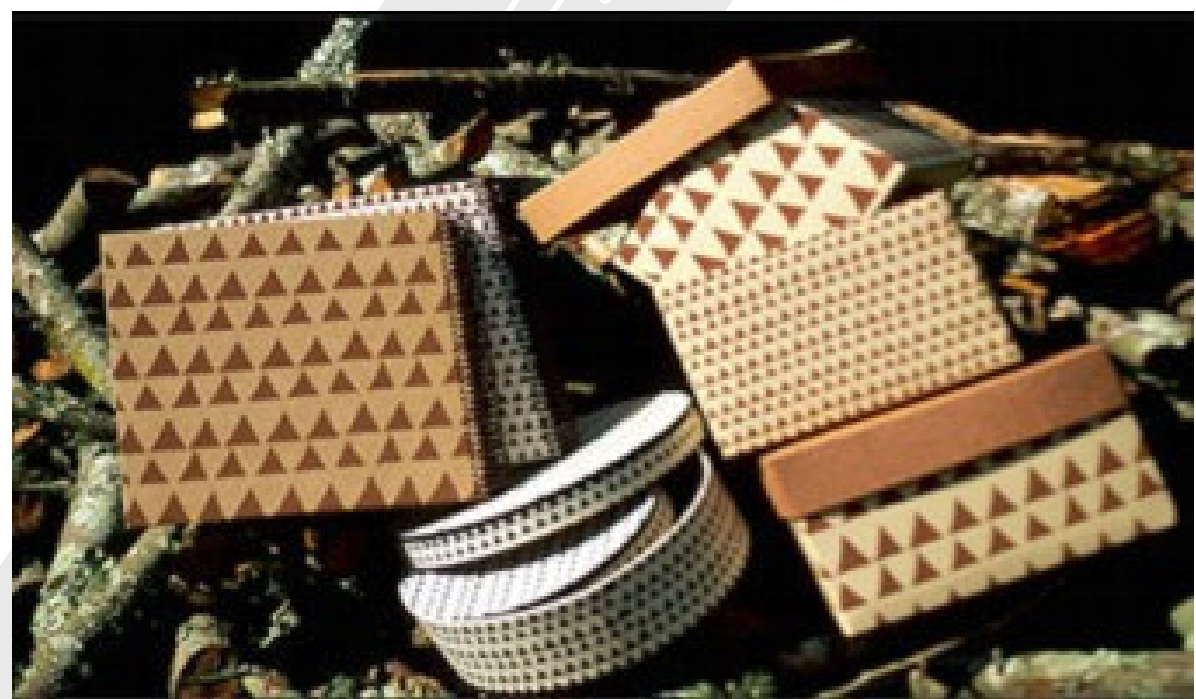

Fonte: <www.acasa.org.br>.

Dessa forma, é possível observar que a maioria dos produtos preocupa-se em manter muitas das características originais do produto artesanal, mesclando-as a novos meios de produção e materiais - itens de papelaria com padrões de estamparia derivados da iconografia guarani - a novos usos - bolsa e colete desenvolvidos a partir do chapéu e sela de vaqueiro - ou a uma nova leitura da forma - sousplat de capim dourado e vestido de renda de bilro. 
A maioria dos produtos selecionados para análise manteve os meios de produção artesanal e, com exceção de alguns trabalhos desenvolvidos pela designer Heloísa Crocco, não objetivaram a comercialização em larga escala, podendo ser esta uma limitação para o uso de materiais rústicos e meios de produção artesanal que, em princípio, devem encarecer o produto.

\section{Considerações finais}

O estudo da cultura de bens materiais encontra força no fato de que os objetos refletem e reproduzem os padrões estéticos, as implicações tecnológicas e a estrutura cultural das sociedades. Nesse sentido, a importância e a responsabilidade do designer no desenvolvimento de produtos tendo como base a releitura de produtos artesanais são destacadas, à medida que a sua performance é crucial à interpretação dos requerimentos simbólicos, estéticos, funcionais e técnicos, além do desenvolvimento da cultura material.

A qualidade estética do produto reflete, portanto, um universo semântico e simbólico, que, decidido pelo "designer-artista", esse produto deve expressar. O interpretativismo, com o designer posicionando-se no baricentro desse processo criativo, passa a ser caracterizado como um dos eventos mais importantes nas sociedades pós-industriais. O objeto não é mais o referente, é a mensagem, tornando o design uma forma expressiva assimilável à arte.

Nesse contexto, este artigo teve como objetivo apresentar, através da observação e leitura de imagens fotográficas, o repertório semântico do artesanato folclórico brasileiro, interpretado, modificado e veiculado como construção de identidade, estilo de vida e expressão de valores e cultura.

Como técnica de observação indireta da realidade social, os métodos visuais - como qualquer outro método de coleta de dados - possuem algumas limitações, pois não dispõem de recursos seguros para penetrar no conteúdo das fotografias, principalmente nesse caso, em que os dados são secundários, e não foi definido pelo pesquisador o que fotografar, quando, quantas vezes e porquê fotografar.

No entanto, a observação comparativa das imagens fotográficas dos diversos produtos estudados permitiu verificar as similaridades e as divergências existentes entre a leitura dos produtos artesanais e a transposição de seus elementos caracterizadores para outros produtos mais adaptados aos padrões de uso globais. Essas leituras do produto artesanal foram mescladas a uma nova releitura da forma ou do uso onde foram reforçados os aspectos estético, simbólico e artístico.

Este estudo conclui que ainda são poucos os trabalhos na área de design realizados nesse sentido. No entanto, pela própria cobrança de um mercado cada vez mais bem informado e preocupado com o ambiente externo, existe uma demanda latente pelo desenvolvimento e fortalecimento de uma identidade nacional impressa nos objetos que manufaturamos, comercializamos e consumimos, como forma de valorizar nossa cultura acrescentando a estes produtos o valor da história de nosso povo, do povo brasileiro. 


\section{Referências}

BIGAL, S. 0 design e o desenho industrial. São Paulo: Annablume, 2001.

BOLOGNINI, D. S. Cultura popular: em busca de nossas raizes. Design e interiores, São Paulo, ano 2, n.9, p.100-101, jul./ago. 1988.

BOSI, A. Reflexões sobre a arte. 6.ed. São Paulo: Ática, 1999.

BRASIL. Ministério da Indústria, do Comércio e do Turismo - MICT. Programa brasileiro de design: documento básico. 2.ed. Brasília, DF: MICT; CNI; Sebrae, 1997.

CARDOSO, R. Uma introdução à história do design. 2.ed. rev. e ampliada. São Paulo: Edgard Blücher, 2004.

CAULFIELD, Jon. Visual sociology and sociological vision, revisited. The American

Sociologist. Fall, 1996. p. 56- 68.

FARIA, A.; GUEDES, A. L. Estudos organizacionais, estratégia e marketing no Brasil: em defesa de uma abordagem focada em consumo e globalização. In: ENCONTRO DE ESTUDOS ORGANIZACIONAIS, 3., 2004, Atibaia, SP. Anais... Atibaia, SP, 2004. 1 CD-ROM.

FERRARA, Lucrecia d'Alessio. Olhar periférico: informação, linguagem, percepção ambiental. 2. ed. São Paulo: EDUSP, 1999.

HESKETT, J. Desenho industrial. Tradução: Fábio Fernandes. 2.ed. Rio de Janeiro: José Olympio, 1998.

MAGALHÃES, C. F. de. Design estratégico: integração e ação do design industrial dentro das empresas. Rio de Janeiro: SENAI/DN, SENAI/CETIOT, CNPq, IBICT, TIB, 1997.

MENDONÇA, J. Ricardo C. de; BARBOSA, Lourdes; DURÃO, André Falcão. Fotografias como um recurso de pesquisa em marketing: o uso de métodos visuais no estudo de organizações de serviços. . ENCONTRO ANUAL DA ANPAD, 28., 2004, Curitiba. Anais... Curitiba: ANPAD, 2004. 1 CD.

NIEMEYER, Lucy. Design no Brasil: origens e instalação. 3. ed. Rio de Janeiro: 2AB, 2000.

PAZ, O. 0 uso e a contemplação. In: BOZAL, V. et al. História geral da arte: artes decorativas I. Espanha: Ediciones del Prado, 1996.

RIBEIRO, Berta G. Arte indígena: linguagem visual. Trad. de Regina Regis Junqueira. Belo Horizonte, 1989.

VERGARA, Sylvia Constant. A utilização da construção de desenhos como técnica de coleta de dados. In: VIEIRA, Marcelo Milano Falcão; ZOUAIN, Deborah Moraes. Pesquisa qualitativa em administração. Rio de Janeiro: FGV, 2004.

VOGT, C. A poética do design. In: LEAL, J. J. Um olhar sobre o design brasileiro. São Paulo: Objeto Brasil, 2002. 